\title{
PENGARUH PERSENTASE FLY ASH TERHADAP KUAT TEKAN HIGH VOLUME FLY ASH SELF COMPACTING CONCRETE SPESIMEN SILINDER 150 MM X 300 MM USIA 90 HARI
}

\author{
Sonny Bhaksono Aji ${ }^{1)}$, Agus Setiya Budi2), Senot Sangadji ${ }^{3)}$ \\ 1) Mahasiswa Program Studi Teknik Sipil Fakultas Teknik Universitas Sebelas Maret \\ 2) Pengajar Program Studi Teknik Sipil Fakultas Teknik Universitas Sebelas Maret \\ 3) Pengajar Program Studi Teknik Sipil Fakultas Teknik Universitas Sebelas Maret \\ Jl.Ir. Sutami 36 A, Kentingan Surakarta 57126. Telp (0271) 647069, Fax 662118 \\ Email : abhaksono@gmail.com
}

\begin{abstract}
The use of pozzolanic supplementary cementing materials such as fly ash in concrete mixture is bighly considerable, it reduces the usage of portland cement and also reuse the underutilized waste from coal burning. High volume fly ash self compacting concrete able to provide sustainable concrete with high mechanical strength and great workability. This study aims to analyze the effect of fly ash content to compressive strength of HVFASCC. The study uses 1 mix design for 28 days normal concrete and 3 different mix design of for 90 days HVFASCC with fly ash replacement ratio 50\%, 60\% and 70\% from $500 \mathrm{~kg} / \mathrm{m}^{3}$ cementitious content. The specimen used is a cylinder $150 \times 300 \mathrm{~mm}$ of 3 pieces for each mix design. Tests include fresh concrete and hardened concrete testing. Destructive tests execute according to ASTM C469 by using compressive testing machine. Fresh concrete test shows that the workability of concrete increasing with the increasing of fly ash replacement ratio. Destructive test generate to evaluate the hardened concrete and the result for NC.90, HVFA.90.50, HVFA.90.60, HVFA.90.70 is 74.98 MPa, 74.60 MPa, 58.95 MPa, 46.50 MPa. The difference value in concrete compressive stress caused by the evolution of the reaction occurring in the fly ash-cement blends that involving degree of bydration and the degree of reaction.
\end{abstract}

Keywords : HV FASCC, concrete properties, fly ash

\begin{abstract}
Abstrak
Penggunaan supplementary cementing material yang bersifat pozzolan seperti fly ash banyak dipertimbangkan karena selain efektif me-reduce penggunaan portland cement, fly ash juga merupakan limbah pembakaran batu bara yang kurang termanfaatkan. High volume fly ash self compacting concrete dapat menghasilkan sustainable concrete dengan mechanical strength yang tinggi dan workability yang baik. Penelitian ini bertujuan untuk menganalisis pengaruh persentase fly ash terhadap kuat tekan HVFASCC. Penelitian menggunakan 1 mix design beton normal usia 28 hari dan 3 variasi mix design HVFASCC usia 90 hari dengan fly ash replacement ratio 50\%, 60\% dan 70\% dengan total cementitious $500 \mathrm{~kg} / \mathrm{m}^{3}$. Spesimen yang digunakan adalah silinder 150 × $300 \mathrm{~mm}$ sejumlah 3 buah untuk tiap mix design. Pengujian yang dilakukan meliputi pengujian beton segar dan hardened concrete. Untuk destructive test dilakukan sesuai standar ASTM C469 dengan compressive testing machine. Hasil pengujian beton segar menunjukkan workability semakin baik seiring peningkatan fly ash replacement ratio. Pengujian hardened concrete untuk NC.90, HVFA.90.50, HVFA.90.60, HVFA.90.70 menghasilkan kuat tekan 74,98 MPa, 74,60 MPa, 58,95 MPa, 46,50 $\mathrm{MPa}$. Adanya perbedaan kuat tekan terjadi karena adanya evolusi dari reaksi yang terjadi pada fly ash-cement blends yang melibatkan degree of bydration dan degree of reaction.
\end{abstract}

Kata Kunci : HVFASCC, properti beton, fly ash

\section{PENDAHULUAN}

Industri konstruksi memberikan environmental impact terbesar dibandingkan aktivitas lain. Setiap tahunnya pekerjaan beton mengkonsumsi 10-11 miliyar ton agregat dan 4,18 miliyar ton semen. Jumlah pekerjaan beton di Indonesia sendiri mencapai 137 juta ton pada tahun 2016 dan diprediksi terus meningkat tiap tahunnya. Telepas dari konsumsi energi yang banyak produksi 1 ton semen menghasilkan 1 ton $\mathrm{CO}_{2}$ dan pada tahun 2007 produksi semen sendiri menyumbang sebanyak 4.4\% dari keseluruhan $\mathrm{CO}_{2}$ yang dihasilkan dari berbagai sumber. Beberapa gagasan diajukan untuk membuat beton lebih sustainable dan hampir semunya mengerucut ke penggunaan supplementary cementing material yang bersifat pozzolan seperti fly ash. Porzolan fly ash banyak dipertimbangkan karena selain efektif me-reduce penggunaan portland cement, fly ash juga merupakan limbah. Pembakaran batu bara menghasilkan miliaran ton fly ash tiap tahunnya. High volume fly ash concrete didefinisikan sebagai beton yang mengandung lebih dari 50\% fly ash dari material cementitious. Self compacting concrete pertama dikembangkan di Jepang pada 1986. SCC memiliki tingkat workability yang baik dimana dapat digunakan dalam pengecoran pada tulangan yang rapat, tanpa membutuhkan vibrator, disamping itu SCC memungkinkan untuk mendapatkan kuat tekan yang tinggi dengan jumlah semen yang reasonable. Hal ini membuktikan bahwa SCC 
cukup reliable untuk digunakan, mengingat desain bangunan dan permintaan beton semakin variatif. Berdasarkan latar belakang tersebut penelitian mengangkat studi tentang high volume fly ash self compacting concrete (HVFASCC).

Beberapa penelitian tentang fly ash concrete sudah pernah dilakukan. Etsuo meneliti bahwa reaksi pozzolanic yang terjadi pada fly ash concrete yaitu beraksinya $\mathrm{Ca}(\mathrm{OH})_{2}$ dengan $\mathrm{SiO}_{2}$ pada fly ash masih dapat diamati dalam jumlah yang signifikan hingga usia 365 hari. Dalam penelitian tersebut juga dibuktikan bahwa pozzolanic reaction tidak terjadi sampai usia 7 hari. Lee menngembangkan model hidrasi untuk fly ash concrete dimana merumuskan bahwa terjadi evolusi yang kompleks pada mikrostruktur fly ash concrete yang membedakan properti fly ash concrete dengan beton normal. Wang melakukan analisis terntang compressive strength development pada high volume fly ash concrete dengan mengkalkulasikan persamaan degree of hydration pada semen yang dikembangkan Tomosawa dan dimodifikasi oleh Park dengan persaamaan yang diurumuskannya yaitu degree of reaction pada fly ash cement belnds. Penelitian sebelumnya belum banyak yang membahas tentang pengaruh persentase fly ash terhadap kuat tekan di HVFASCC, pun kebanyakan hanya di usia 28 hari dan dengan fly ash replacement ratio yang relatif rendah. Padahal untuk diaplikasikan dalam desain perencanaan dan perancangan struktur dibutuhkan properti beton tersebut. Oleh karena itu penelitian ini bertujuan untuk menganalisis pengaruh persentase fly ash terhadap kuat tekan HVFASCC dengan spesimen silinder 150 × $300 \mathrm{~mm}$ usia 90 hari.

\section{DASAR TEORI}

Pemakaian fly ash akan menurunkan kekuatan awal beton, namun dengan masih berlangsungnya reaksi pozzolanic maka kekuatan beton akan meningkat dalam jangka waktu yang lama. Reaksi kimia yang terjadi pada beton normal yaitu hidrasi $\mathrm{C}_{3} \mathrm{~S}$ dan $\mathrm{C}_{2} \mathrm{~S}$ adalah sebagai berikut :

$$
\begin{aligned}
2\left(3 \mathrm{CaO} \cdot \mathrm{SiO}_{2}\right)+6 \mathrm{H}_{2} \mathrm{O} & \stackrel{\text { Cepat }}{\longrightarrow} 3 \mathrm{CaO} \cdot \mathrm{SiO}_{2} \cdot 3 \mathrm{H} 2 \mathrm{O}+3 \mathrm{Ca}(\mathrm{OH})_{2} \\
2 \mathrm{C} 3 \mathrm{~S}+6 \mathrm{H} & \stackrel{\text { cepat }}{\longrightarrow} \mathrm{C}-\mathrm{S}-\mathrm{H} \text { gel }+3 \mathrm{CH} \\
2\left(2 \mathrm{CaO} \cdot \mathrm{SiO}_{2}\right)+4 \mathrm{H}_{2} \mathrm{O} & \stackrel{\text { Cepat }}{\longrightarrow} 3 \mathrm{CaO} . \mathrm{SiO}_{2} .3 \mathrm{H} 2 \mathrm{O}+\mathrm{Ca}(\mathrm{OH})_{2} \\
2 \mathrm{C}_{2} \mathrm{~S}+4 \mathrm{H} & \stackrel{\text { Cepat }}{\longrightarrow} \text { C-S }-\mathrm{H} \text { gel }+\mathrm{CH}
\end{aligned}
$$

$\mathrm{Ca}(\mathrm{OH})_{2}$ sendiri adalah produk hidrasi reaksi dari semen dengan air yang memiliki sifat rapuh dan larut di dalam air. Kalsium hidroksida yang dihasilkan akan membuat sifat basa kuat $(\mathrm{pH}=12,5)$. Hal ini menyebabkan beton sensitif terhadap asam (Nugraha, 2007). Kalsium hidroksida dalam beton mudah sekali bereaksi dengan asam membentuk garam yang berdampak pada pengeroposan beton. Fly ash mengandung silika atau silika alumina yang memiliki sedikit atau tidak ada sifat semen tetapi apabila dalam bentuk butiran yang halus dan kondisi lembab, bahan ini dapat bereaksi secara kimia dengan $\mathrm{Ca}(\mathrm{OH})_{2}$ membentuk senyawa bersifat cementitious. Reaksi antara silika dengan kapur berlangsung sangat lambat, sehingga diperlukan waktu umur yang cukup lama untuk mencapai hasil kuat tekan yang optimal. Reaksi kimia $\mathrm{Ca}(\mathrm{OH})_{2}$ dengan $\mathrm{SiO}_{2}$ adalah sebagai berikut :

$$
\begin{aligned}
3 \mathrm{Ca}(\mathrm{OH})_{2}+\mathrm{SiO}_{2}+\mathrm{H}_{2} \mathrm{O} & \stackrel{\text { Lambat }}{\longrightarrow} 3 \mathrm{CaO} . \mathrm{SiO}_{2} .3 \mathrm{H}_{2} \mathrm{O} \\
3 \mathrm{CH}+\mathrm{Si}+\mathrm{H} & \stackrel{\text { Lambat }}{\longrightarrow} \text { C-S-H gel }
\end{aligned}
$$

Dengan mencampurkan bahan pozolan pada jumlah yang sesuai dengan semen, unsur aktif $\mathrm{SiO}_{2}$ akan bereaksi secara sekunder dengan $\mathrm{Ca}(\mathrm{OH})_{2}$ untuk menghasilkan kalsium hidrosilikat. Menurut Mochamad Solikin(2011) pemakaian fly ash sebagai pengganti sebagian semen berguna terutama untuk meningkatkan durabilitas beton, karena kandungan silica $\left(\mathrm{SiO}_{2}\right)$ di dalam fly ash yang tinggi akan mengikat $\mathrm{Ca}(\mathrm{OH})_{2}$ untuk menghasilkan $\mathrm{CSH}$ (Calcium Silicat Hydarate), senyawa utama yang membangun kekuatan beton. Terlihat bahwa fly ash sebagai filler yang berfungsi mengisi rongga-rongga kapiler (capillary porous) pada beton dan bereaksi dengan kapur bebas yaitu $\mathrm{Ca}(\mathrm{OH})_{2}$ membentuk $\mathrm{CSH}$ gel yang menyebabkan beton akan lebih padat, lebih kuat serta lebih kedap dan memiliki performa yang tinggi.

\section{METODE PENELITIAN}

Jenis penelitian yang dilakukan merupakan jenis eksperimen di bidang civil engineering dengan metode kuantitatif. Berdasarkan tipe pemakaiannya penelitian ini termasuk applied science. Penelitian ini akan dilakanakan selama 9 bulan, dimulai di bulan september 2017 dan diakhiri di bulan mei 2018. Penelitian dilaksanakan di Laboratorium MIPA Terpadu, Laboratorium Teknik Mesin, Laboratorium Struktur dan Laboratorium Bahan Fakultas Teknik Universitas Sebelas Maret Surakarta. Sebelum proses mix design terlebih dahulu dilakukan pengujian material.

Pada agregat halus pengujian yang dilakukan adalah kandungan lumpur dalam pasir, kandungan zat organik dalam pasir, spesific gravity agregat halus (SNI 1970 2008) dan gradasi agregat halus (ASTM C136). Pada agregat kasar pengujian yang dilakukan adalah spesific gravity agregat kasar (SNI-1969-2008), abrasi agregat kasar (SNI2417-2008), gradasi agregat kasar (ASTM C136). Pada fly ash pengujian yang dilakukan adalah pengujian berat 
jenis (SNI 1964 2008) dan uji kadungan fly ash dengan XRF. Standar spesifikasi material yang digunakan adalah ASTM C-33, ASTM C-128 dan PBI 1971.

\section{Mix Design}

Perencanaan mix design dilakukan mengikuti prosedur SNI-03-2384-2000 dan menyesuaikan EFNARC 2002 untuk ketentuan-ketentuan SCC. Setelah mix design dibuat dilakukan beberapa kali trial dan adjustment sehingga beton memenuhi parameter-parameter SCC yang disyaratkan. Adjustment diperlukan karena beton yang dibuat adalah bigh volume fly ash concrete dimana belum ada standar bakunya. Pada penelitian ini HVFASCC akan diuji pada umur 90 hari, sedangkan beton normal pada 28 hari. Hal ini dikarenakan high volume fly ash concrete masih mengalami penambahan kuat tekan hingga usia 90 hari, namun beton normal mencapai 100\% dari kekuataanya pada usia 28 hari. Kadar cementitious adalah sama untuk semua varian yaitu $500 \mathrm{Kg} / \mathrm{m}^{3}$ dengan water to binder ratio adalah 0,27 dan 0,3 untuk HVFASCC dan beton normal, persentase admixture adalah $2 \%$ dan $1 \%$ untuk HVFASCC dan beton normal. Pada penelitian ini digunakan tiga variasi fly ash replacement ratio terhadap material cementitious, yaitu 50\%, 60\% dan 70\%. Masing-masing varian memiliki 3 buah spesimen untuk diuji.

Tabel 1. Mix Proportion

\begin{tabular}{ccccccc}
\hline Sampel & $\begin{array}{c}\text { OPC } \\
\mathrm{Kg} / \mathrm{m}^{3}\end{array}$ & $\begin{array}{c}\text { Fy ash } \\
\mathrm{Kg} / \mathrm{m}^{3}\end{array}$ & $\begin{array}{c}\text { Pasir } \\
\mathrm{Kg} / \mathrm{m}^{3}\end{array}$ & $\begin{array}{c}\text { Kerikil } \\
\mathrm{Kg} / \mathrm{m}^{3}\end{array}$ & $\begin{array}{c}\text { Air } \\
\mathrm{lt} / \mathrm{m}^{3}\end{array}$ & $\begin{array}{c}\mathrm{SP} \\
1 \mathrm{t} / \mathrm{m}^{3}\end{array}$ \\
\hline NC.90 & 500 & 0 & 687.38 & 1059.26 & 150 & 5 \\
\hline HVFA.90.50 & 250 & 250 & 865.73 & 889.40 & 135 & 10 \\
\hline HVFA.90.60 & 200 & 300 & 863.19 & 886.79 & 135 & 10 \\
\hline HVFA.90.70 & 150 & 350 & 860.65 & 884.18 & 135 & 10 \\
\hline
\end{tabular}

\section{HASIL DAN PEMBAHASAN}

\section{Pengujian Beton Segar}

Parameter yang ditinjau untuk pengujian beton segar adalah, filling ability, passing ability dan segregation retention. Pengujian beton segar dilakukan untuk memastikan bahwa HVFA yang dibuat adalah HVFASCC. Hasil pengujian dapat dilihat pada tabel berikut.

Tabel 2. Hasil Pengujian Beton Segar

\begin{tabular}{cccccc}
\hline Sampel & $\begin{array}{c}\text { Abrams } \\
(\mathrm{mm})\end{array}$ & $\begin{array}{c}\mathrm{T}_{50 \mathrm{~cm}} \\
(\text { detik })\end{array}$ & L-box & $\begin{array}{c}\text { V-funnel } \\
\text { (detik) }\end{array}$ & $\begin{array}{c}T_{5 \text { minute }} \\
\text { (detik) }\end{array}$ \\
\hline HVFA.90.50 & 658.5 & 4.6 & 0.83 & 11.7 & +1.4 \\
\hline HVFA.90.60 & 674 & 4.2 & 0.91 & 10.2 & +1.5 \\
\hline HVFA.90.70 & 733.5 & 3.2 & 0.98 & 9.8 & +2.6 \\
\hline
\end{tabular}

Kesimpulannya adalah semakin besar persentase fly ash yang digunakan maka workability akan semakin baik. Berbeda dengan semen yang memiliki geometri prismatik, fly ash memiliki bentuk yang rounded sehingga akan memberikan bidang gelincir yang lebih baik untuk agregat. Semen hampir tidak memiliki dormant period, sehingga jika semen terkena air maka akan langsung terjadi proses hidrasi, mengeras dan bentuknya pun juga berubah. Hal ini tidak terjadi pada fly ash yang memiliki dormant period lama, walaupun terkena air fly ash masih bisa mem-provide workability yang baik.

\section{Pengujian Hardened Concrete}

Pengujian kuat tekan dilakukan dengan menggunakan standar ASTM C469 dengan menggunakan compressive testing machine. Hasil destructive test untuk hardened concrete dapat dilihat pada tabel 3.

Tabel 3. Pengujian Hardened Concrete

\begin{tabular}{ccc|}
\hline Benda Uji & Kuat Tekan Maksimum $(\mathrm{MPa})$ & Rerata Kuat Tekan (MPa) \\
\hline NC.90.A & 75.263 & \multirow{2}{*}{74.980} \\
\hline NC.90.B & 74.697 & \\
\hline NC.90.C & 74.980 & \multirow{2}{*}{74.602} \\
\hline HVFA.90.50.A & 74.414 & \\
\hline HVFA.90.50.B & 74.697 & \multirow{2}{*}{58.946} \\
\hline HVFA.90.50.C & 74.697 & \\
\hline HVFA.90.60.A & 59.135 & \multirow{2}{*}{46.497} \\
\hline HVFA.90.60.B & 58.852 & \\
\hline HVFA.90.60.C & 58.852 & \\
\hline HVFA.90.70.A & 46.403 & \\
\hline HVFA.90.70.B & 46.403 & \\
\hline HVFA.90.70.C & 46.685 & \\
\hline
\end{tabular}


High volume fly ash concrete mengalami penambahan kuat tekan di usia 90 hari secara signifikan. Berdasarkan hasil uji coba yang dilakukan, yaitu mencari kuat tekan high volume fly ash concrete di usia 28 hari dengan mix design yang sama. Komparasi hasil pengujian $f^{\prime} c$ dapat dilihat pada gambar 1 di bawah ini.

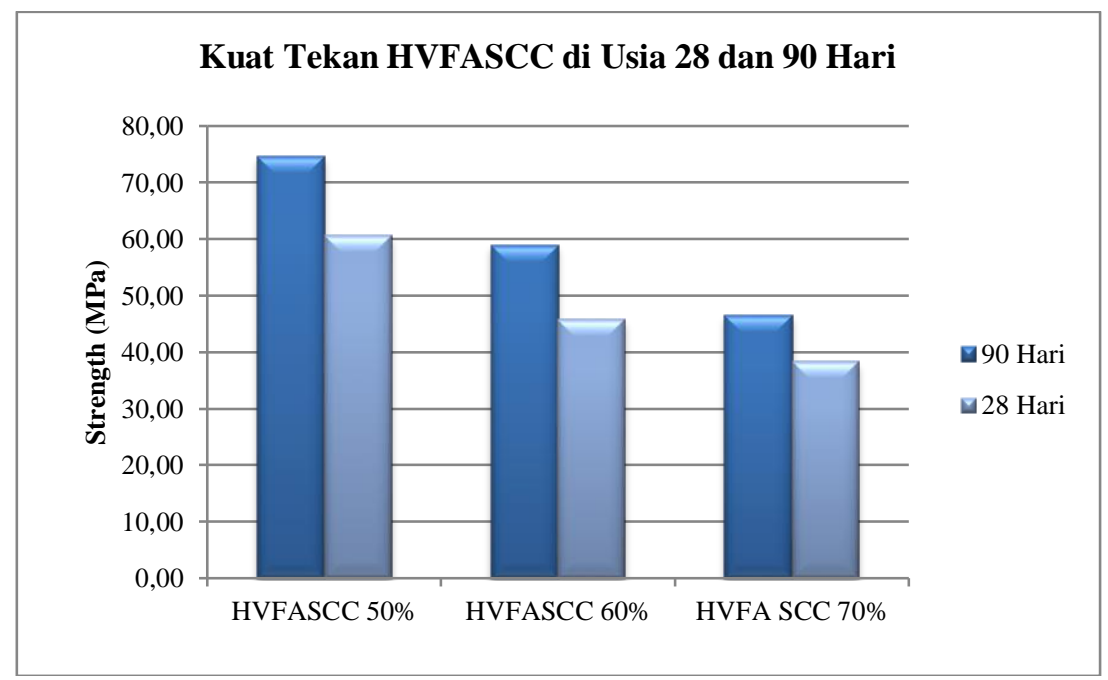

Gambar 1. Perbandingan Kuat Tekan HVFASCC Usia 28 dan 90 Hari

Strength development antara HVFA.28 ke HVFA.90 dan antara HVFA.90.50, HVFA.90.60, HVFA.90.70 dikarenakan fly ash memiliki dormant period yang lama dan bereaksi setelah $\mathrm{pH}$ 13.3. Kondisi ini dibutuhkan untuk memecah glass phase, sehingga fly ash tidak bisa berkontribusi di early strength development. Reaksi hidrasi yang terjadi pada fly ash hanya berlangsung pada permukaan hingga ke ketebalan 0.3-0.4 $\mu \mathrm{m}$, sehingga di akhir reaksi volume phase fraction dari fly ash relatif banyak dibandingkan semen. Strength evolution dari high volume fly ash concrete dipengaruhi oleh degree of reaction dari fly ash yang persamaan numerik terhadap fungsi waktu, disamping itu pozzolanic reaction dalam fly ash cement blends masih dapat diamati dalam jangka waktu yang lama. Evolusi dari kalsium hidroksida, chemically bound water dan capillary water di cement-fly ash blends bergantung kepada degree of bydration dari semen dan degree of reaction dari fly ash.

Pada high volume fly ash concrete, ketika digunakan fly ash replacement $60 \%$ hingga $70 \%$ berarti semen yang digunakan hanya 40\% dan 30\%. Jumlah semen 40\% dan 30\% tersebut akan bereaksi dengan keseluruhan air, karena semen hampir tidak mempunyai dormant period sementara pada waktu yang sama fly ash masih dalam dormant period. Akhirnya timbul porositas di awal reaksi yang mengakibatkan interlocking yang kurang kuat dan beton lebih mudah meregang sehingga elastisitasnya turun. Pernyataan ini dibuktikan dengan tabel 3 dimana semakin besar persentase fly ash yang digunakan maka kekuatannya pun juga semakin menurun

\section{SIMPULAN}

Penelitian ini membahas tentang hubungan kuat tekan pada bigh volume fly ash self compacting concrete. Hasil pengujian fresh concrete HVFA.90.50, HVFA.90.60 dan HVFA.90.70 memenuhi semua kriteria SCC. Hasil menunjukkan semakin banyak persentase fly ash yang digunakan maka workability juga semakin baik. Pada umur 90 hari HVFA.90.50 memiliki kuat tekan yang sama dengan beton normal di usia 28 hari dengan jumlah material cementitious yang sama. Hubungan kuat tekan HVFA.90 memenuhi hubungan $f^{\prime} \mathrm{c}_{\mathrm{NC} .90}=f^{\prime} c_{\mathrm{HVFA} .90 .50}<f^{\prime} c_{\mathrm{HVFA} .90 .60}<$ $f^{\prime} c_{\text {HVFA.90.70. }}$

\section{REKOMENDASI}

a. Perlu penelitian longitudinal, mengingat degree of reaction dari high volume fly ash concrete masih mengalami peningkatan hingga usia 365 hari.

b. Penelitian dengan mix design lain untuk mengetahui perilaku konkrit dari HVFASCC

c. Analisis dan evaluasi secara detail tentang hubungan antara reaksi kimia dan chemical properties pada HVFASCC dengan properti-properti pada HVFASCC, termasuk didalamnya strength development, strength evolution, degree of bydration dan degree of reaction dari cement fly ash blends.

d. Radiogical experiement dari high volume fly ash concrete perlu dilakukan untuk mengetahui tingkat keamaannya ketika digunakan dalam suatu konstruksi. 


\section{UCAPAN TERIMAKASIH}

Ucapan terima kasih pertama ditujukan kepada Allah SWT atas limpahan rahmat dan nikmatnya. Selanjutnya kepada Agus Setiya Budi, S.T., M.T. dan Dr. Senot Sangadji, S.T., M.T.selaku dosen pembimbing yang telah memberi arahan dan masukan dalam penelitian ini.

\section{REFERENSI}

Anonim, 2015, USGS, Minerals Yearbook, Cement, US geological survey, United States Department of the Interior, http://minerals.usgs.gov/ minerals/pubs/ commodity/cement/mcs-2015-cemen.pdf.

Anonim, 2014, The Carbon Dioxide Information Analysis Center, Oak Ridge National Laboratory, U.S. Department of Energy, Oak Ridge, Tenn.

Anonim, 2010, ACI Committee 363, Report on High-Strength Concrete, ACI Farmington Hills, Michigan.

Anonim, 2002, ASTM C 469, Standard Test Method for Static Modulus of Elasticity andPoisson's Ratio of Concrete in Compression, ASTM International, West Conshohocken, Pennsylvania, USA.

Anonim, 2002, EFNARC, The European Guidelines for Self-Compacting Concrete, United Kingdom.

Anonim. 2000, SNI 03-2834-2000, Tata Cara Pembuatan Rencana Campuran Beton Normal, Badan Standarisasi Nasional, Jakarta.

Boden. T.A, Marland. G, Andres. R.J, 2010, Global, Regional, and National Fossil-Fuel CO 2 Emissions, Carbon Dioxide Information Analysis Center, Oak Ridge National Laboratory, U.S. Department of Energy, Oak Ridge, Tenn.

Etsuo Sakaia, Shigeyoshi Miyaharab, Shigenari Ohsawaa, Seung-Heun Leec, Masaki Daimona, 2004, Hydration of fly ash cement, Department of Metallurgy and Ceramics Science, Graduate School of Science and Engineering, Tokyo Institute of Technology, Tokyo, Japan.

Han Seung Lee, Xiao Yong Wang, 2010, Modelling the Hydration of Concrete Incorporating Fly ash or Slag, Cement and Concrete Research, School of Architecture \& Architecturaal Engineering, Hanyang University, Ansan, Republic of Korea.

Malhotra, V.M., 2002, High-performance high-volume fly ash concrete, Concrete Int.

Meyer. C, 2002, Concrete and Sustainable Development, Special Publication ACI206, American Concrete Institute, Farmington Hills, M.I., U.S.A.

Xiao-Yong Wang, Ki-Bong Park, 2015, Analysis of Compressive Strength Development of Concrete Containing High Volume Fly ash, Department of Architectural Engineering, Kangwon National University, Chuncheon, Republic of Korea. 